\title{
Study on the Present Situation and Promotion Path of Entrepreneurship Development in Yulin City
}

\author{
Jiang Liu ${ }^{1, a^{*}}$ Xinzhuo Jiang ${ }^{2, b}$ Dawei Gao ${ }^{3, \mathrm{c}}$ \\ ${ }^{1}$ School of Management, Yulin University, China, 719000 \\ ${ }^{2}$ School of Foreign Languages, Yulin University, China, 719000 \\ ${ }^{3}$ Yulin Public Employment and Talent Service Center, China, 719000 \\ a52186531@qq.com, b250883726@qq.com, ${ }^{\mathrm{a}}$ 156652641@qq.com
}

\section{Keywords: Entrepreneurship; Development; Promotional path}

\begin{abstract}
Under the current background of "mass entrepreneurship and innovation", this paper constructs the theoretical framework of "entrepreneurial" policy environment by studying the current situation of entrepreneurship development in Yulin and the existing problems, and explores the practical path of developing Yulin's entrepreneurship according to the theoretical framework of policy environment in order to speed up transformation and upgrading of economic and social transformation in Yulin, achieve catch-up and provide useful substantive help as well as detailed and accurate scientific basis for Yulin entrepreneurial innovation by leaps and bounds.
\end{abstract}

\section{Research Overview at Home and Abroad}

At the Third Plenary Session of the 18th CPC Central Committee on November 12, 2013, "The Decision to Comprehensively Deepen Reform" was made, which required to "improve and promote the employment and entrepreneurship system", "improve the preferential policy to support entrepreneurship and form a new mechanism in which the government motivates entrepreneurship, the society supports entrepreneurship and workers dare to start a new business". By June 16, 2015, the State Council promulgated the "Opinions on Some Measures for Vigorously Promoting Innovation for the Massive Start-up of Enterprises", in which specific measures to cultivate and promote "massive entrepreneurship and innovation" as a new force for economic and social development. Since then, a new strategic layout of national development has basically taken shape.

At present, China's economy has entered a new normal and behind the new normal are the factors such as the optimization of the economic structure, the switch of growth momentum and the change of the institutional environment. The voices from official and non-governmental sources have also been put forward constantly. The theoretical basis of macro-control under the new normal should be adjusted and new macro-control tools should constantly be explored. The proposal of "mass entrepreneurship and mass innovation" is obviously closely linked with the current new normalcy of the economy, embodying the central authorities' insight into the situation and a new change in the mentality of governing the country and administration. In recent years, the "Entrepreneurship Trend" started from Zhongguancun in Beijing has rapidly spread to Shenzhen, Shanghai, Tianjin, Sichuan and Guizhou. The surging "Entrepreneurship Trend" has not only inspired the passion and dream of countless people, but also indicates that we will usher in a brand-new era of "mass entrepreneurship and innovation".

Based on this, there are a large number of studies on entrepreneurship and innovation at home and abroad, but the emphases are different. Professor Stephenson (2015) of the University of Netherlands has long been devoted to studying the SMEs' entrepreneurship and innovation system. He pointed out that the government's support of the entrepreneurs through the innovation lottery system is mainly from the number of knowledge industrialization projects, the scale of knowledge conversion projects and the speed of knowledge industrialization. This part details how the Dutch government supports social entrepreneurship through innovative lottery systems. Professor Hibert (2015) at Yale University in the United States has been studying the federal technology transfer promotion bill for a long time. He believes that an important way to promote innovation and entrepreneurship is to promote technology management and transfer. While strengthening the protection of intellectual property rights, there is a 
need to actively promote scientific research institutions or large companies to transfer some research results to start-ups.

Although it is only two years since the concept of "mass entrepreneurships and innovation" was first proposed, many scholars in China have conducted in-depth researches in this field. Xiao Haiyang (2015) proposed to promote "mass entrepreneurship and innovation" in China by simplifying power, reducing taxes for small businesses, educating and drawing lessons from foreign countries. Wang Lin (2015) believes that small and micro enterprises have more innovative vitality, and if they can solve the difficulty in enterprises' overall management and immature management, they can further release the vitality of enterprises and promote innovation and entrepreneurship. Professor Wan Gang (2015) pointed out that with close development of science, innovation and development, it is necessary to firmly grasp the tremendous potential of science and technology and industrial reform and the glorious scientific and technological innovation of institutional reform. Besides, it was necessary to speed up the development of science and technology service industry and create a good situation in the whole society . According to Li Chunhua (2015.), the key to advancing the mass entrepreneurship and innovation lies in promoting innovation and entrepreneurship, promoting and protecting innovation, promoting the open sharing of science and technology resources, and accelerating the creation of mass innovation space. According to Du Gang (2015.), under the background of "mass innovation for the general public", the mode of personnel training at colleges and universities should be innovated at the same time. We should pay attention to the combination of theoretical teaching and practical teaching, improve the system of entrepreneurship and rescue, encourage students to enter the society, strengthen cooperation between schools and enterprises, and strive for more entrepreneurial opportunities for students.

\section{Significance}

In today's era, we must further study and vigorously promote "mass entrepreneurship and mass innovation", that is, "double creation", explore and give birth to new momentum in the development of SMEs in China and the entire national economy, and make efforts to eliminate the problems that are unfavorable to the innovation and development of entrepreneurship as well as all kinds of system shackles that will effectively break the institutional mechanisms and policy malpractices and hinder the innovation and development of entrepreneurship, activate the wisdom and creativity of hundreds of millions of people in an all-round way, and better realize the capital chain to guide the innovation chain and the innovation chain of entrepreneurship. To support the industrial chain and the industrial chain as well as the formation and healthy development of the employment chain and the sustained and healthy development of our economy has played an important role in deepening the theory and policy practice in China.

As of Yulin, to vigorously promote the "public entrepreneurship" is a solid priority to promote employment strategy to start a job and promote employment; Yulin City is currently at a crucial stage of the social restructuring, industrial upgrading and the transformation of urban functions. By promoting the implementation of "mass entrepreneurship", forming new employment channels and exploring new production technologies, we can not only effectively reduce the employment pressure brought about by the readjustment of industrial structure, but also better promote the innovation of science and technology and production methods. "Mass entrepreneurship" not only helps to further improve the efficient allocation of resources, promote better and faster growth of economy and society in a sustained and healthy manner, but also helps promote the expansion of employment scope and fields and create more and better new supplies. This is of great significance for Yulin to achieve the grand goal of "three areas and one highland" and "catching up and surpassing".

In August 2015, Yulin Municipal Government proposed "Opinions on Further Implementing Employment and Entrepreneurship in the New Situation", aiming at further promoting employment and entrepreneurship, implementing a more active employment policy, and establishing and improving the government's incentives for entrepreneurship and innovation and social support for entrepreneurial innovation mechanism in which laborers bravely start their own businesses. However, there are still many problems to be solved in the process of entrepreneurship development in Yulin City: the knowledge level 
and entrepreneurial skills of entrepreneurs need to be improved; whether entrepreneurial opportunities are equal; whether the entrepreneurial environment is friendly; whether the entrepreneurial resources are reasonable, fair and effective.

\section{Contents of Research}

Main Contents of Research. 1 Current development of entrepreneurship in Yulin; 2 Assessment of Yulin's entrepreneurial and policy environment; 3 Strategies and suggestions to promote the entrepreneurship development in Yulin; 4 The key point is to summarize the current situation of entrepreneurship in Yulin by means of investigation and comparative method, evaluate the policy environment, and provide feasible opinions and suggestions. 5 The difficulty of this project is to put forward relevant and feasible suggestions and opinions.

\section{Basic Thoughts and Methods}

The main contents of the research are the status quo of Yulin's entrepreneurial development and promotional path. Based on the key elements of entrepreneurship and with culture and education, financial support, policy support and platform construction as the four major focal points, in-depth investigation and analysis of Yulin's entrepreneurial status is carried out from 4 aspects: culture, economy, politics and society. And strategies and suggestions to promote the development of entrepreneurship in Yulin are proposed.

The main methods used include: documentation, field research, interview and comparison.

\section{Acknowledgements}

Planning Project: Special fund planning project of social science federation in Yulin city in 2017. (Project Number: YLSKGH2017-16)

Yulin university-industry cooperation project in 2016 (Project Number: 2016CXY-10)

\section{References}

[1] J.Q. Zhang: Forum on Science and Technology in China, (2017) No.1, p.305 (In Chinese)

[2] Zh.H. Yang: Modern Management Science, (2016) No.7, p.45 (In Chinese)

[3] Sh.Z. Gu: Hubei Social Sciences, (2016) No.7, p. 87 (In Chinese)

[4] H, Yu and W.W. Ye: Research in Higher Education of Engineering, (2016) No.3, p.100 (In Chinese)

[5] Ch.H. Tao: China Development Observation, (2016) No.4, p.56(In Chinese)

[6] Sh.M.Hui: Review of Economic Research, (2016) No.7, p.36 (In Chinese)

[7] Sh.C. Zhang: Reform of Economic System, (2016) No.1, p.14(In Chinese)

[8] Y.Q. Liu, F.Y. Lv and J. Mao: Journal of Chinese Academy of Governance, (2016) No.6, p.35 (In Chinese)

[9] Ch.M. Wang and T. Wu: Journal of Zhejiang University(Humanities and Social Sciences) , (2016) No.1, p.131 (In Chinese)

[10] W. Lv: Frontiers , (2015) No.22, p.6 (In Chinese) 